\title{
BLAUZDOS TIESIAMŲJŲ IR LENKIAMUৃJŲ RAUMENŲ FUNKCIJOS KITIMAS IZOKINETINIO KRŪVIO METU
}

\author{
Ronaldas Endrijaitis ${ }^{1}$, Arūnas Krasauskas ${ }^{3}$, Vytautas Streckis ${ }^{2}$, Julija Andrejeva ${ }^{2}$, \\ Giedrius Gorianovas $^{2}$, Irena Vitkien $\dot{e}^{2}$, Aleksas Stanislovaitis ${ }^{2}$, Vytautas Markevičius ${ }^{3}$ \\ Generolo Jono Žemaičio Lietuvos karo akademijal ${ }^{1}$,Vilnius, Lietuvos kūno kultūros akademija ${ }^{2}$, Kaunas, \\ Mykolo Romerio universitetas ${ }^{3}$, Vilinius, Lietuva
}

\begin{abstract}
Ronaldas Endrijaitis. Sporto mokslų magistras. Lietuvos kūno kultūros akademijos doktorantas. Mokslinių tyrimų kryptis — Generolo Jono Žemaičio lietuvos karo akademijos kariūnų motorinès sistemos darbingumas ir adaptacija prie fizinių krūvių.
\end{abstract}

\section{SANTRAUKA}

Tyrimo tikslas — nustatyti ir palyginti Generolo Jono Žemaičio Lietuvos karo akademijos pirmo kurso kariūnu (LKA) ir Didžiojo Lietuvos etmono Jonušo Radvilos mokomojo pulko šauktiniu (JRMP) blauzdos tiesiamuju ir lenkiamuju raumenu funkcini pajèguma, atsparumq nuovargiui ir atsigavima. LKA kariūnu $(n=17)$ amžiaus vidurkis $18,8 \pm$

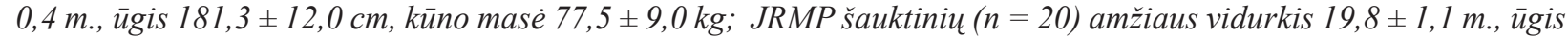

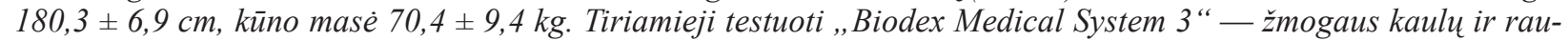
menu testavimo ir reabilitacijos ìranga. Prieš krūvĭ, iš karto po jo ir praejus 5 minutèms po krūvio buvo matuojama maksimalioji valinga momentine jéga (MVMJ) (3 kartus tiesiant ir lenkiant koja per kelio sqnari vidutiniu greičiu $\left(180^{\circ} /\right.$ s)). Fizinis krūvis — 100 blauzdos tiesimo ir lenkimo judesiu vidutiniu greičiu.

MVMJ testavimo metu tiesiant blauzda LKA kariu sumažejo iki 40,45\%, JRMP šauktiniu — iki 43, 75\%. Lenkiant blauzda, MVMJ rodikliai LKA kariu sudarè 43,6\% pradinès reikšmés, JRMP šauktiniu — 39,1\%, lyginant su pradine reikšme.

Rezultatai parodè, kad LKA kariu, lyginant su JRMP šauktiniais, MVMJ tiek prieš krūvì, tiek atsigavimo metu buvo didesné; raumenu atsparumas nuovargiui ir atsigavimas tiek tiesiant blauzda, tiek lenkiant ja iš esmés tiriamuju grupése buvo panašūs. ¿̨domu tai, kad ir LKA kariūnu, ir JRMP šauktiniu MVMJ nuostoliai ryškiausi atlikus 50 tiesimo judesiu, tuo tarpu tokia MVMJ kaita blauzdos lenkiamuosiuose raumenyse pasireiškia atlikus 30 judesiu.

Raktažodžiai: izokinetinis krūvis, maksimalioji valinga momentinè jëga, raumenu nuovargis ir atsigavimas.

\section{IVADAS}

$\check{Z}$ mogaus griaučių raumenų funkcinès galimybès, adaptaciniai mechanizmai ir funkcinio pajègumo didinimo būdai visada domino mokslininkus ir tyrejus. Raumenu geba padidinti jègą priklauso nuo daugelio veiksnių, tokių kaip raumenų masé, raumenų audinio tipas ir jų suaktyvinimo savybės (Skurvydas, 1998).

Griaučių raumenys, kurių masė sudaro apie $40-50 \%$ suaugusio žmogaus kūno masès, yra žmogaus judamojo aparato aktyvioji dalis ir geba adaptuotis - prisitaikyti prie ịvairių veiklos sąlygu (Costill et al., 1979).

Šiu dienų kariuomeneje vienas iš svarbiu kiekvieno vado uždaviniu - ìvertinti karių fizinę ir dvasinę būklę, žinoti, kaip ją gerinti (Dadelo, 1998; Endrijaitis, Radžiukynas, 2003). Kariams rengti naudojamos priemonès turi būtų tokios, kad jie jaustų pasitenkinimą tarnyba, aiškiai suvoktų ginkluotujų pajègų tikslus, tiksliai laikytųsi karinès tarnybos taisyklių ir vykdytu isakymus. 
Užduoties ir tikslų igyvendinimo sèkmè labai priklauso nuo gebejimo sekti ir vertinti karių organizmo fizinių ir psichinių galių kaitą (Radžiukynas, 1999), labai svarbu žinoti, kaip organizme vyksta adaptacijos procesai taikant fizinius krūvius ar atliekant užduotis sudètingomis sąlygomis (Fitts et al., 1991; Skurvydas, 1991).

Problema. Neaišku, ar stojančių i Lietuvos karo akademija jaunuoliu ir šaukiamuju i privalomają karo tarnybą fizinis parengtumas skiriasi. Atliktas eksperimentas galbūt padès iš dalies atskleisti panašios veiklos institucijas sąmoningai pasirenkančio ir privalomosios tarnybos kontingento fizinio pajègumo tendencijas.

Šio tyrimo tikslas - nustatyti ir palyginti Generolo Jono Žemaičio Lietuvos karo akademijos pirmo kurso kariūnų ir Didžiojo Lietuvos etmono Jonušo Radvilos mokomojo pulko šauktinių blauzdos tiesiamujų ir lenkiamujų raumenų funkcini pajejgumą, atsparumą nuovargiui ir jų atsigavimą po izokinetinio krūvio.

\section{TYRIMO METODIKA}

Tiriamieji. Tyrimas atliktas Lietuvos kūno kultūros akademijos „Žmogaus motorikos” laboratorijoje. Buvo tiriami sveiki Generolo Jono Žemaičio Lietuvos karo akademijos (LKA) kariūnai $(\mathrm{n}=17)$, kurių amžiaus vidurkis $18,8 \pm 0,4 \mathrm{~m}$, ūgis $181,3 \pm 12,0 \mathrm{~cm}$, kūno masè $77,5 \pm 9,0 \mathrm{~kg}$, ir Didžiojo Lietuvos etmono Jonušo Radvilos mokomojo pulko (JRMP) šauktiniai $(\mathrm{n}=20)$, kurių amžiaus vidurkis $19,8 \pm 1,1 \mathrm{~m}$, ūgis $180,3 \pm 6,9 \mathrm{~cm}$, kūno masè 70,4 $\pm 9,4 \mathrm{~kg}$.

Dinamometro nustatymas ir sureguliavimas. Tyrimas atliktas naudojant specializuotą testavimo ir reabilitacijos izokinetini dinamometrą (Biodex Medical System 3 PRO. Sertifikuota ISO 9001 EN 46001). Tiriamajam atsisėdus ị specialią kèdę, dešinè koja fiksuojama prie dinamometro pritvirtintu papildomu kelio įtaisu. Nustačius anatominę kelio sąnario aši, kuri turejo sutapti su dinamometro ašimi, tiriamasis apjuosiamas pečių kryžminiais ir liemens, šlaunies skersiniais diržais. Blauzda sutvirtinta diržu su sagtimi apjuosiama apatiniame trečdalyje, $4 \mathrm{~cm}$ virš kulnakaulio gumburo. Nustatoma testuojamos kojos lenkimo amplitudè (ištiesus ir sulenkus blauzdą per kelio sąnari), koja pasveriama per kelio sąnari sulenkta $60^{\circ} \pm$ $5^{\circ}$ kampu (sunkio jègos momentu).

Blauzdos tiesiamujų ir lenkiamujų raumenų maksimalioji valinga momentinè jèga (toliau MVMJ) buvo nustatoma fizinị krūvị atliekant vidutiniu greičiu $\left(180^{\circ} / \mathrm{s}\right)$. Testuojant visi tiriamieji buvo nuolat raginami žodžiais didžiausiomis pastangomis įveikti pasipriešinimą (Montgomery et al., 1989). Testavimas buvo atliktas izokinetiniu režimu pagal toliau pateiktą protokolą.

\section{Eksperimento eiga:}

- Pramankšta: 5 minučiu veloergometro mynimas $60-70 \mathrm{~W}$ galingumu (pulso dažnis 110 - 130 tv. / min).

- 5 minučių poilsis prieš testą; jo metu nustatomas dinamometras ir sureguliuojama kèdès padètis.

- Keturi bandomieji blauzdos tiesimo ir lenkimo per kelio sąnari judesiai $(25,50,75$, $100 \%$ jègos) nustatyta judesio amplitude.

- Testas: kontrolinis testavimas prieš krūvị: 1 serija po 3 blauzdos tiesimo ir lenkimo judesius $180^{\circ} / \mathrm{s}$ kampiniu greičiu. 1 minutès poilsis tarp atliekamų judesių.

- Fizinis krūvis: 100 blauzdos tiesimo ir lenkimo judesiu $180^{\circ}$ / s kampiniu greičiu.

- Kontrolinis testavimas iš karto po krūvio: 1 serija po 3 blauzdos tiesimo ir lenkimo judesius $180^{\circ} / \mathrm{s}$ kampiniu greičiu.

- 5 minučių kontrolinis testavimas po krūvio: 1 serija po 3 blauzdos tiesimo ir lenkimo judesius $180^{\circ}$ / s kampiniu greičiu.

Matematinè statistika. Skaičiuotas gautų rezultatú aritmetinis vidurkis $(\bar{x})$, standartinis nuokrypis (S). Rezultatu skirtumo patikimumas nustatytas taikant Stjudento ( $\mathrm{t}$ ) (Student $t$ ) kriterijų. Skirtumas laikomas statistiškai reikšmingu, jei $\mathrm{p}<0,05$. Skaičiavimas atliktas naudojant statistinių skaičiavimų programini paketą Microsoft (R) Excel 2003.

\section{REZULTATAI}

Lyginant LKA kariūnų ir JRMP šauktinių blauzdos tiesiamujų raumenų MVMJ pradinius rodiklius nustatyta, kad LKA kariūnų MVMJ $(155,5 \mathrm{~N} \cdot \mathrm{m})$ buvo didesnè $(\mathrm{p}<0,05)$ nei JRMP šauktiniu (120,9 N.m) (2 pav.) Po izokinetinio krūvio statistiškai patikimai sumažèjo $(\mathrm{p}<0,05)$ MVMJ tiek JRMP šauktinių (52,9 N.m), tiek LKA kariūnu $(62,9 \mathrm{~N} \cdot \mathrm{m})$ - tai sudarè atitinkamai 43,75 ir $40,45 \%$, lyginant su pradiniais duomenimis. Praejus 5 minutèms po izokinetinio krūvio, atsigavimo metu, JRMP šauktinių MVMJ buvo 108,7 N·m, LKA kariūnų - 137,0 N·m (2 pav.), ir tai sudarè atitinkamai 89,9 ir $88,1 \%$ pradinès reikšmès.

Tiriamuju grupems atliekant 100 dinaminių blauzdos tiesiamujų raumenu judesių nustatyta, 

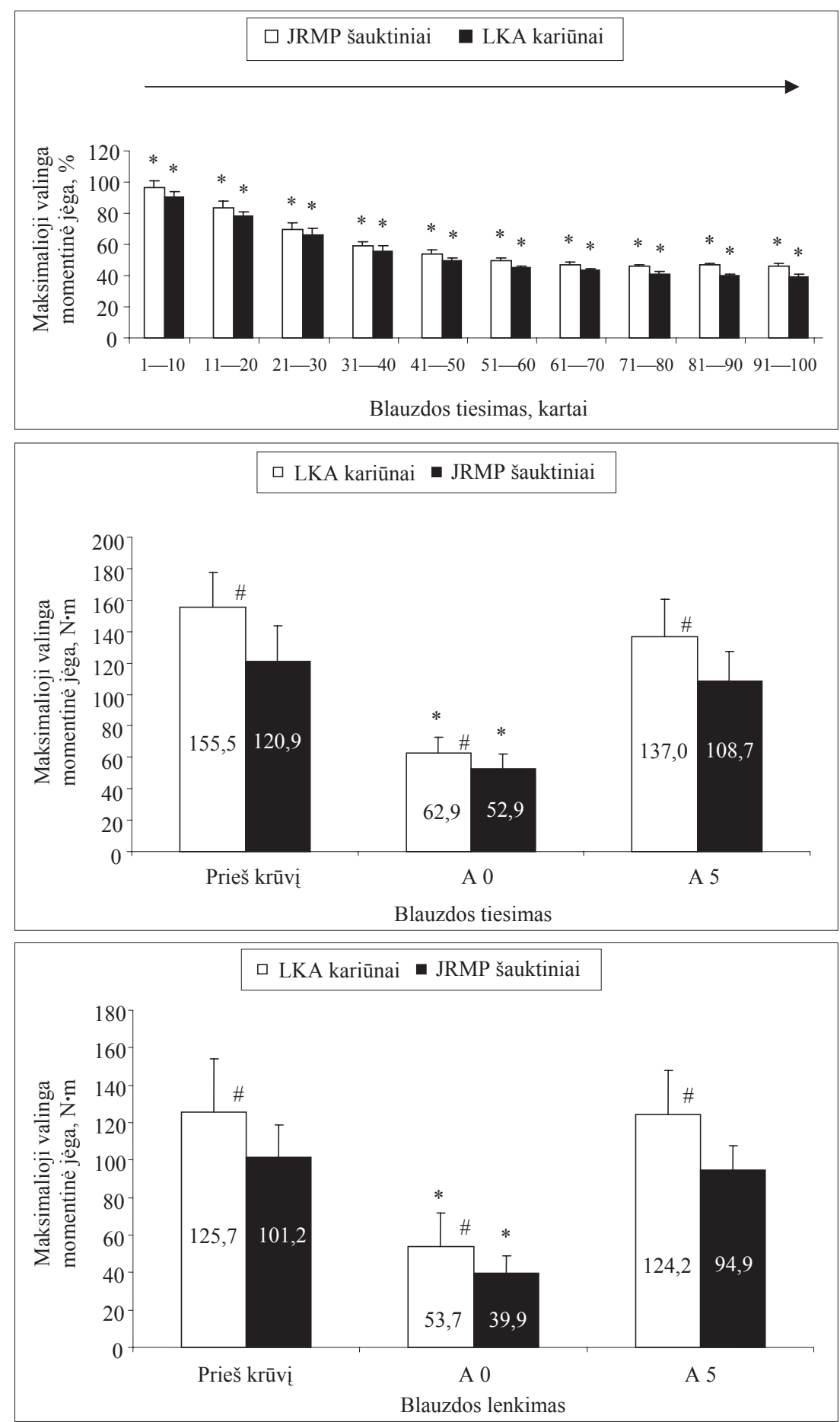

1 pav. LKA kariūnų ir JRMP šauktinių blauzdos tiesiamųjų raumenų maksimaliosios valingos momentinès jègos kaita izokinetinio krūvio metu

Pastaba. * — skirtumas patikimas, lyginant su pradine reikšme $(\mathrm{p}<0,05)$.

2 pav. LKA kariūnų ir JRMP šauktinių blauzdos tiesiamųjų raumenų maksimalioji valinga momentinė jèga prieš krūvị, iš karto po krūvio (A 0 ), praèjus 5 min po jo (A 5)

Pastaba. \# - skirtumas patikimas tarp grupių $(\mathrm{p}<0,05)$; * - skirtumas patikimas grupejje, lyginant su pradinėmis reikšmėmis $(\mathrm{p}<0,05)$.

3 pav. LKA kariūnų ir JRMP karių blauzdos lenkiamųjų raumenų maksimalioji valinga momentinė jèga prieš krūvị, iš karto po krūvio (A 0), praèjus 5 min po jo (A 5)

Pastaba. \# - skirtumas patikimas tarp grupių $(\mathrm{p}<0,05)$; * skirtumas patikimas grupeje, lyginant su pradinèmis reikšmèmis $(\mathrm{p}<0,05)$. kad MVMJ daugiausia mažèjo abiejose grupèse $(\mathrm{p}<0,05)$ iki 60 judesio. Vèliau abieju grupių tiriamujų blauzdos tiesiamujų raumenų MVMJ pakito mažiau ( $\mathrm{p}>0,05)$ (1 pav.).

Lygindami abiejų grupių testuojamujų rodiklių kitimo kreives (1 pav.) nustatème, kad LKA kariūnų MVMJ kaita pirmoje krūvio pusèje santykiškai didesnè nei JRMP šauktinių, nors nuovargis po krūvio abiejose grupèse statistiškai reikšmingai nesiskyrè (2 pav.). JRMP šauktinių MVMJ procentinè reikšmè atlikus pusę fizinio krūvio (50 tiesimo ir lenkimo judesių), lyginant su pradine reikšme, sudarè 54,8\%, LKA kariūnų 50,6\%. Antroje krūvio pusejje abiejose grupése MJMJ kitimas nebuvo toks ryškus $(p>0,05)$. Po atlikto izokinetinio testo kelio tiesiamujų raumenų MVMJ abiejose tirtose grupėse statistiškai reikšmingai nesiskyrè $(\mathrm{p}>0,05)$.

Lygindami LKA kariūnų ir JRMP šauktinių blauzdos lenkiamujų raumenų MVMJ pradinius (prieš krūvị) rodiklius nustatėme, kad LKA kariūnu MVMJ $(125,7 \mathrm{~N} \cdot \mathrm{m})$ buvo didesnè $(\mathrm{p}<0,05)$ nei JRMP šauktinių (101,2 N·m) (3 pav). MVMJ po izokinetinio krūvio statistiškai patikimai suma- 
4 pav. LKA kariūnų ir JRMP šauktinių blauzdos lenkiamųjų raumenų maksimaliosios valingos momentinès jègos kaita izokinetinio krūvio metu

Pastaba. * - skirtumas patikimas grupeje, lyginant su pradiniais duomenimis $(\mathrm{p}<0,05)$.

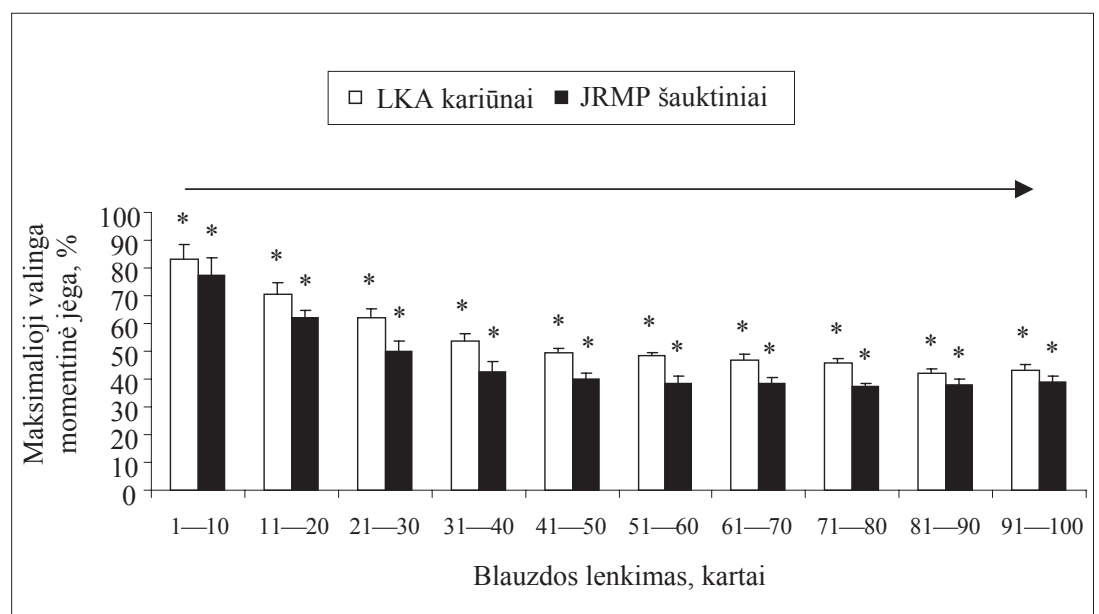

žèjo $(\mathrm{p}<0,05)$ : JRMP šauktinių - iki 39,9 N·m, LKA kariūnu — iki 53,7 N·m, ir tai sudarè atitinkamai $39,42 \%$ ir $42,72 \%$, lyginant su pradiniais duomenimis. Praejus 5 minutems po izokinetinio krūvio, JRMP šauktinių MVMJ buvo 94,9 N·m, tuo tarpu LKA kariūnų - 124,2 N.m (4 pav.), ir tai atitinkamai sudare $93,77 \%$ ir $98,8 \%$.

Tiriamuju grupėms atliekant 100 blauzdos lenkimo judesių nustatyta, kad MVMJ didžiausi nuostoliai pasireiške iki 40 judesio (4 pav.), palyginti su pradine reikšme $(\mathrm{p}<0,05)$. Panašu, kad lyginant su kelio tiesiamaisiais raumenimis lenkiamujų raumenų nuovargio slenkstis pasireiškè anksčiau. Vèliau abieju grupių tiriamujuc blauzdos lenkiamujų raumenų MVMJ kito mažiau ( $\mathrm{p}>0,05)$ (4 pav.).

Lygindami abieju grupių testuojamujų rezultatu kitimo kreives (4 pav.) nustatėme, kad JRMP šauktinių MVMJ kaita santykiškai didesnè nei LKA kariūnu ( $p<0,05)$. JRMP šauktinių MVMJ procentinè reikšmè atlikus 30 lenkimo judesiu, palyginti su pradine reikšme, sumažèjo $57,5 \%$, o LKA kariūnu — 46,4\%. Nuo 40 lenkimo judesio iki krūvio pabaigos JRMP šauktiniu MVMJ sumažèjo 3,4\%, LKA kariūnų - 10,2\%. Po viso izokinetinio testo JRMP šauktiniu MVMJ sumažèjo 60,9\%, LKA kariūnu - 56,6\% (4 pav.). Lyginant tirtąsias grupes, kelio lenkiamuju raumenų MVMJ po krūvio statistiškai reikšmingai nesiskyrè $(\mathrm{p}<0,05)$

\section{REZULTATUQ APTARIMAS}

Pagrindinis šio tyrimo tikslas buvo nustatyti ir palyginti Generolo Jono Žemaičio Lietuvos karo akademijos (LKA) kariūnų ir Didžiojo Lietuvos etmono Jonušo Radvilos mokomojo pulko (JRMP) šauktinių blauzdos tiesiamujų ir lenkiamujų raumenų nuovargị ir atsigavimą izokinetinio krūvio metu. Pagrindinè tyrimų išvada ta, kad LKA kariūnų kelio tiesiamujų ir lenkiamujų raumenų funkcinis pajègumas didesnis ir jègos rodikliai atsigauna greičiau. LKA kariūnų ir JRMP šauktinių MVMJ rodikliai atlikus pusę fizinio krūvio (50 tiesimo ir lenkimo judesių) mažèjo labiau nei antroje krūvio pusejje (1 pav), vèliau kito nedaug. Panašias jègos kitimo tendencijas nustate ir S. Kamandulis (2004), tirdamas maksimalaus intensyvumo kartotinius vertikalius šuolius. Blauzdos lenkiamuju raumenu MVMJ kinta labiau atlikus 40 lenkimo judesių. Taigi didesnis lenkiamujų raumenu MVMJ sumažejjimas pasireiške anksčiau.

Nuo kokių fiziologinių mechanizmu priklauso MVMJ kitimas krūvio metu? Vienas iš jų — raumenų nuovargis - priklauso nuo autoaktyvuojamu mechanizmų, kurių paskirtis gerinti, ekonomizuoti raumenų veiklą ir priešintis nuovargiui. Sporto medicinos literatūroje tai įvardijama kaip posttetaninè potenciacija (Mačiukas, 1999). Be to, kaip raumens nuovargio mediatorius krūvio metu dalyvauja ir pieno rūgštis, kuri yra raumenų nuovargio kilmès metabolinis veiksnys (Allen, Westerblad, 2004). Pastaroji disocijuoja ị laktatą ir vandenilio jonus, kurie konkuruoja su kalcio jonais dèl jungimosi prie troponino $\mathrm{C}$, ir gali pabloginti raumens susitraukiamumą (Weicker, 1995).

LKA kariūnų kelio tiesiamujų raumenų nuovargis pirmoje krūvio pusèje buvo didesnis nei JRMP savanorių. Tai būtų galima paaiškinti šitaip: raumenys, kuriuose vyrauja 1 tipo (lètosios) skaidulos, yra atsparesni nuovargiui, palyginti su raumenimis, kuriuose vyrauja 2 tipo (greitosios) raumeninès skaidulos (Fitts, 1994). Be to, ir greituju raumeninių skaidulu jègos rodikliai aukštesni (Stasiulis et al., 2005). Mūsų tyrimo rezultatai rodo, kad LKA kariūnų blauzdos tiesiamuju ir lenkiamujų raumenu MVMJ buvo didesnè tiek prieš krūvi, tiek po jo, lyginant su JRMP šauktinių duomenimis. 
Abiejų grupių tiriamujų blauzdos tiesiamujų ir lenkiamujų raumenų MVMJ rodikliai krūvio metu rodo panašią nuovargio kaitą. Blauzdos lenkiamieji raumenys pavargsta mažiau nei tiesiamieji. Panašius duomenis pateikia ir kiti tyrejjai (Wilke et al., 1987; Perrin et al., 1987).

LKA kariūnų ir JRMP šauktinių blauzdos tiesiamujų raumenu MVMJ rodikliai (2 pav.) iš karto po krūvio statistiškai patikimai sumažèjo $(\mathrm{p}<0,05)$, palyginti su pradinėmis reikšmèmis. Po krūvio LKA kariūnų blauzdos tiesiamuju raumenų MVMJ sumažèjo 92,6 N·m, JRMP karių $68,0 \mathrm{~N} \cdot \mathrm{m}$. Praejjus 5 minutems po izokinetinio krūvio, abieju grupių tiriamujų blauzdos tiesiamuosiuose raumenyse pastebeti atsigavimo požymiai.

LKA kariūnų blauzdos lenkiamujų raumenų MVMJ po krūvio sumažèjo iki 72,0 N·m, JRMP kariu — iki $61,3 \mathrm{~N} \cdot \mathrm{m}$. Praejjus 5 minutèms po izokinetinio krūvio abiejų grupių tiriamujų blauzdos lenkiamieji raumenys atsigavo (skirtumas atitinkamai 1,5 ir $6,3 \mathrm{~N} \cdot \mathrm{m}$, lyginant su pradiniais rodikliais) (4 pav.).

Nelieka abejoniu, kad maksimalaus intensyvumo fiziniai pratimai sukèlè metabolini nuovargi, kuris pasireiškè abiejų grupiu karių blauzdos tiesiamuosiuose ir lenkiamuosiuose raumenyse. Metabolinio nuovargio metu labiausiai sumažèja ATP hidrolizès ir resintezès greitis, energinių medžiagu kiekis raumenyse, ypač kreatinfosfato ir glikogeno, mažèja miofibriliu jautrumas $\mathrm{Ca}^{2+}$ (Brenner 1988; Westerblad, Allen, 2003). Krūvio metu susikaupę metabolitai blokuoja miozino skersiniu tiltelių ciklišką darbą, todèl mažejja raumens susi- traukimo jèga, galingumas ir jo atsipalaidavimo greitis. Panašu, kad lenkiamuosius raumenis tai mažiau veikia. Abiejų grupių tiriamujų blauzdos tiesiamujų raumenų MVMJ rodikliai prieš krūvị, krūvio metu, iš karto po jo ir atsigavimo metu (5 min po krūvio) nustatyti didesni nei lenkiamujų. Keturgalvis šlaunies raumuo pavargsta greičiau, nuovargio pasekmès išlieka ilgiau. İdomu tai, kad lenkiamujų raumenų jègos mažèjimas stabilizuojasi anksčiau nei tiesiamujuc, o jègos kitimo skirtumų tarp tiriamuju grupių nenustatyta (1, 3 pav.). Po maksimalaus intensyvumo krūvio raumenyse gerokai padidèja vandenilio jonų koncentracija. Manoma, kad raumenų skaidulos mioplazmoje padaugèja $\mathrm{Ca}^{2+}$, dèl kurių vèliau atsiranda nuovargis (Westerblad, Allen, 1993). KF koncentracija po tokio krūvio tampa visiškai normali praejjus $2-3$ minutems, vandenilio jonu koncentracija - po 10-15 minučių, Raumens potenciacija po didžiausio intensyvumo krūvio išlieka apie 5-10 minučiu (Skurvydas, 1998). Taigi šios veiksniu grupès galèjo lemti atsigavimo rodiklius mūsu tyrimo atveju.

\section{IŠVADA}

Generolo Jono Žemaičio Lietuvos karo akademijos kariūnų blauzdos tiesiamuju ir lenkiamujų raumenų maksimalioji valinga momentinè jèga, lyginant su Didžiojo Lietuvos etmono Jonušo Radvilos mokomojo pulko šauktiniais, didesnè tiek izokinetinio krūvio, tiek atsigavimo metu po jo. Atsparumo nuovargiui ir atsigavimo rodiklių reikšmingo skirtumo tirtose grupèse nenustatyta.

\section{LITERATŪRA}

Aagaard, P., Simonsen, E. B., Trolle, M., Bangsbo, J., Klausen, K. (1995). Isokinetic hamstring / quadriceps strength ratio: Influence from joint angular velocity, gravity correction and contraction mode. Acta Physiologica Scandinavica, 154, 421-427.

Allen, D., Westerblad, H. (2004). Physiology. Lactic acid-the latest performance-enhancing drug. Science, 305, $1112-1113$

Brenner, B. (1988). Effect of $\mathrm{Ca}^{2+}$ on cross-bridge tumover kinetics in skinried single fibers: Implication of muscle contraction II Proc. National Academy of Sciences (USA), $85,3542-3546$.

Costtill, D. L., Coyle, E. F., Fink, W. F. (1979). Adaptations in skeletal muscle following strength training. Journal of Applied Physiology, 46, 96.

Dadelo, S. (1998). Lietuvos teisès akademijos studentu fizines saviugdos efektyvumo tyrimai: daktaro disertacija. Vilnius.
Endrijaitis, R., Radžiukynas, D. (2003). Generolo Jono Žemaičio Lietuvos karo akademijos pirmo kurso kariūnu fizinio rengimo ypatumai. Ugdymas. Küno kultūra. Sportas, 5, 8-13.

Fitts, R. H. (1994). Cellular mechanisms of muscle fatigue. Physiological Reviews, 74 (J), 49-94.

Fitts, R. H., McDonald, K. S., Schluter, J. M. (1991). The determinants of skeletal muscle force and power: Their adaptability with changes in activity pattern. Journal of Biomechanics, 24 (1), 111-122.

Kamandulis, S. (2004). Pakartoto krūvio efektas po raumens pažeidq sukeliančiu fiziniu pratimu: daktaro disertacija. Kaunas. P. 48-58.

Mačiukas, A. (1999). Griaučiu raumenu nuovargio ir aktyvacijos sqveika maksimalaus intensyvumo krūvio ir atsigavimo po jo metu: daktaro disertacijos santrauka. Kaunas.

Montgomery, L., Douglass, L., Deuster, P. (1989). Reliability of an isokinetic test of muscle strength and endurance. 
Journal of Orthopaedic and Sports Physical Therapy, 10, 315-322.

Perrin, D. H., Robertson, R. J., Ray, R. L. (1987). Bilateral isokinetic peak torque, torque acceleration energy, power, and work relationships in athletes and nonathletes. Journal of Orthopaedic and Sports Physical Therapy, 9 (5), 184189.

Radžiukynas, D. (1999). Lietuvos karo akademijos kariūnu fizinis ugdymas pirmais studiju metais: daktaro disertaci$j a$. Vilnius: Vilniaus pedagoginis universitetas.

Rose, T., Engel, T., Bernard, J. (2004). Differences in the rehabilitation period following two methods of anterior cruciate ligament replacement; semitendinosus / gracilis tendon vs. ligamentum patellae. Knee Surgery Sports Traumatology Arthroscopy, 12 (3), 189-197.

Skurvydas, A. (1998). Judesiu valdymo ir sporto fiziologijos konspektai: metodine priemone. Kaunas: LKKI. P. $20-21$.

Skurvydas, A. (1991). Organizmo adaptacijos prie fizi- niu krūviu pagrindiniai dèsningumai. II dalis. Kaunas. P. 61.

Stasiulis, A., Dubininkaitè, L., Venckūnas, T. (2005). Sporto ir pratimu fiziologijos laboratoriniai darbai. Kaunas. P. $33-37$.

Weicker, H. (1995). Einflus metabolisher faktoren auf statishe und dynamishe Kraft sowie periphere Ermudung. Deutshe Zeitschrift fur Sportmedizin, 3, 151-168.

Westerblad, H., Allen, D. G. (2003). Cellular mechanisms of skeletal muscle fatigue. Advances in Experimental Medicine and Biology, 538, 563-570.

Westerblad, H., Duty, S., Allen, D. G. (1993). Intracellular calcium concentration during low-frequency fatigue in isolated single fibers of mouse skeletal muscle. Journal of Applied Physiology, 75 (1), 382-388.

Wilke, K. E., Johnson, R. D., Levine, B. (1987). A comparison of peak torque values of knee extension and flexor muscle groups using Biodex, Cybex and Kin-Com isokinetic dynamometers. Physical Therapy, 67 (6), 789-790.

\title{
SHIN FLEXOR AND EXTENSOR MUSCLE FUNCTION CHANGES DURING ISOKINETIC WORKLOAD
}

\author{
Ronaldas Endrijaitis ${ }^{1}$, Arūnas Krasauskas ${ }^{3}$, Vytautas Streckis ${ }^{2}$, Julija Andrejeva ${ }^{2}$, \\ Giedrius Gorianovas $^{2}$, Irena Vitkiené ${ }^{2}$, Aleksas Stanislovaitis ${ }^{2}$, Vytautas Markevičius ${ }^{3}$ \\ General Jonas Žemaitis Military Academy of Lithuania ${ }^{1}$,Vilnius, Lithuanian Academy of Physical \\ Education ${ }^{2}$, Kaunas, Mykolas Romeris University ${ }^{3}$,Vilnius, Lithuania
}

\begin{abstract}
Research aim was to determine and compare the General Jonas Zemaitis Military Academy (LMA) of Lithuania 1st year cadets and etymon Jonush Radvila Training Regiment Conscript (JRTR) soldiers' shin extensor and flexor muscle functional capability, fatigue resistance and recovery process.

Methods. The subjects were LMA cadets $(\mathrm{n}=17)$ age $18.8 \pm 0.4 \mathrm{~m}$, height $181.3 \pm 12.0 \mathrm{~cm}$, body mass $77.5 \pm 9.0 \mathrm{~kg}$ respectively; JRTR soldiers $(\mathrm{n}=20)$ age $19,8 \pm 1,1 \mathrm{~m}$, height $180.3 \pm 6.9 \mathrm{~cm}$, body mass $70.4 \pm$ $9.4 \mathrm{~kg}$. Research subjects were assessed by Biodex Medical System 3 PRO Certificated ISO 9001 EN 46001 research and rehabilitation device. Maximal voluntary muscle contraction (MVC) was assessed before the workload, 1 min right after it, and 5 min after the workload, ( 3 times flexion and extension of knee flexor muscles at average angular speed $\left(180^{\circ} / \mathrm{s}\right)$. The workload was 100 shin muscles flexion-extension movements. MVC during the workload muscle extension movement for LMA cadets decreased by $40.45 \%$; and for JRTR conscripts it decreased by $43.75 \%$ accordingly. Thus, during shin flexion MVC indexes for LMA cadets were $43.6 \%$ of initial indexes, and JRTR conscripts achieved $39.1 \%$ compared to the initial indexes.

Conclusions: research results showed, that LMA cadets' indexes compared to JRTR conscripts' MVC indexes were higher before the workload and during the recovery time after the workload; muscle resistance to fatigue and recovery indexes during shin extensor and flexion had no significant difference. It is worth noting that LMA cadets and JRTR conscripts MVC wastage was most obvious after performing 50 extension movements, MVC decrease dynamics in shin flexor muscles appeared after performing 30 movements.
\end{abstract}

Keywords: isokinetic dynamometer, isokinetic workload, maximal voluntary contraction, muscle fatigue, recovery.

Gauta 2007 m. sausio $27 \mathrm{~d}$.

Received on January 27, 2007

Priimta $2008 \mathrm{~m}$. birželio $18 \mathrm{~d}$.

Accepted on June 18, 2008
Ronaldas Endrijaitis

Generolo Jono Žemaičio Lietuvos karo akademija

(General Jonas Žemaitis Military Academy of Lithuania)

Šilo g. 5 A, LT-10322 Vilnius

Lietuva (Lithuania)

$\mathrm{Tel}+37052103635$

E-mail ronaldas_endrijaitis@hotmail.com 